\title{
An exploration of the Logic and wisdom behind the Marriage of the Dead
}

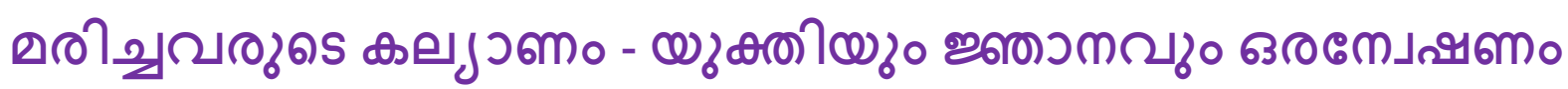

\section{R. Chandrabose ${ }^{a, *}$}

a Department of Malayalam, School of Languages and Comparative Literature, Central University of Kerala, Kerala - 671316, India

*Corresponding author Email: bosebosechandra@gmail.com

DOI: https://doi.orq/10.34256/ijmrd2015

Published: 26-01-2021s

Abstract: Kasargod is the North East district of Kerala and shares a border with Karnataka, 'Marriage of the dead is a custom among the tribal communities known as Moger and Koppalar. In this paper, the logic behind this practice and the wisdom that civil society should embody from it will be found.

Keywords: Marriage of the dead, Tulu language, Ritual, Memory, Magic.

Language: Malayalam

\section{About the Author}

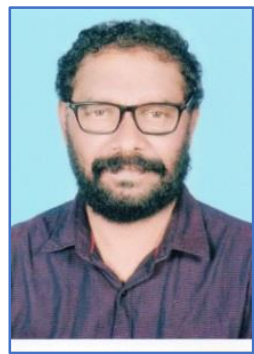

Dr. R. Chandrabose, working as an Assistant professor in the Department of Malayalam, under School of languages and comparative literature, Central University of Kerala, The Central University of Kerala is located in Kasargod, a district of Kerala, came into being in2009, under the central universities act 2009. Dr.R.Chandrabose authored three books in Malayalam, Myth and modern Malayalam poetry, Nation of poetry, Book of life and death.

லேிவுவ०

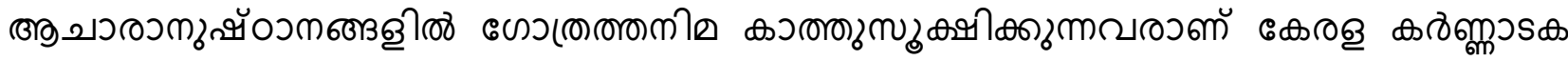

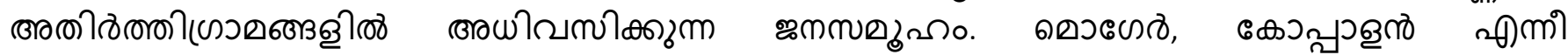

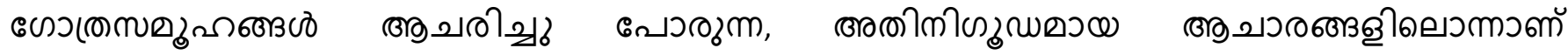

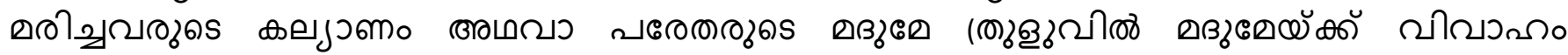

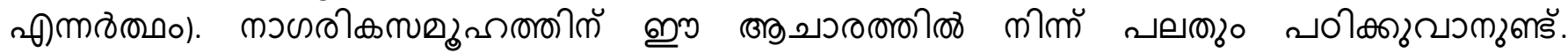

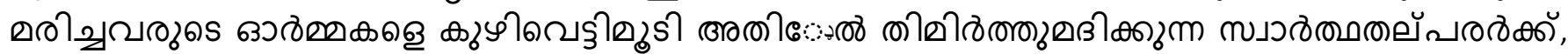

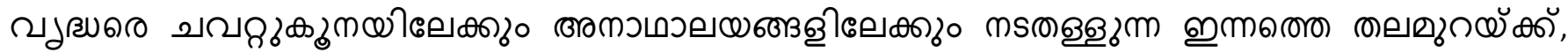

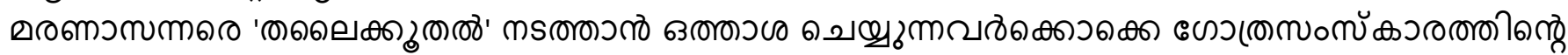

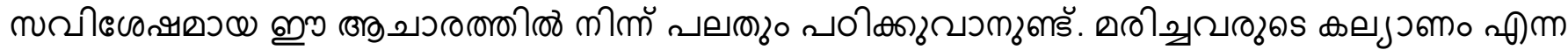

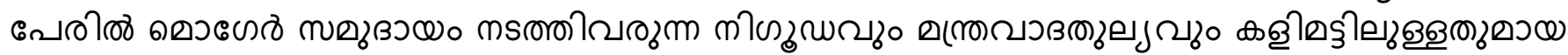

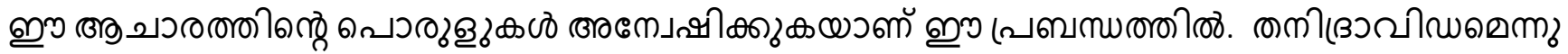




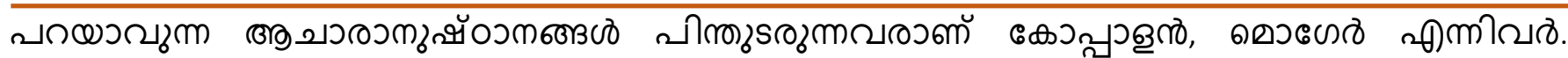

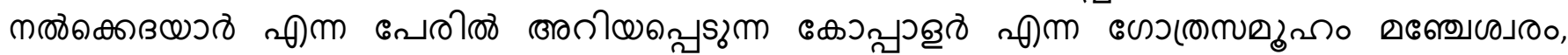

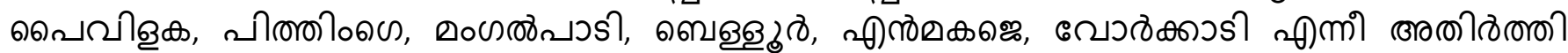

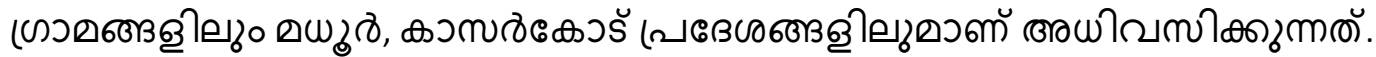

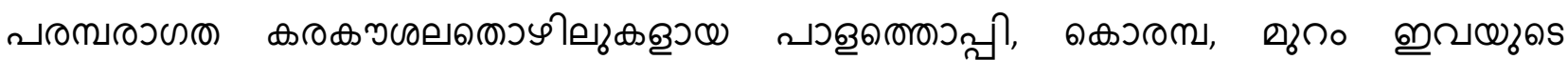

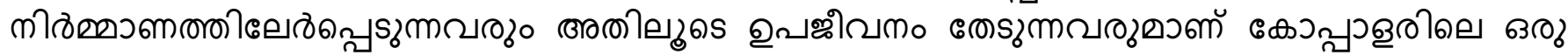

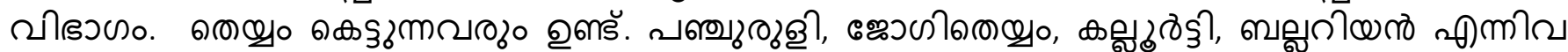

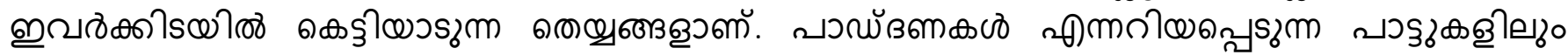

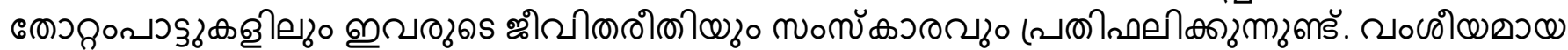

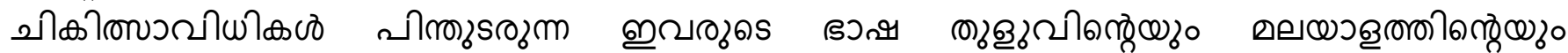

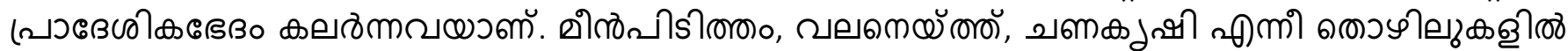

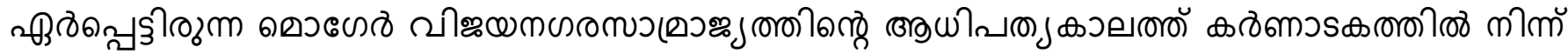

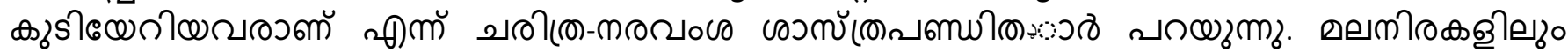

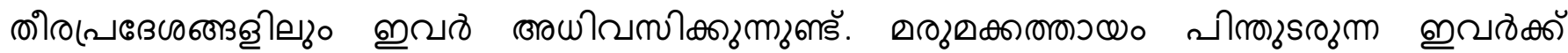

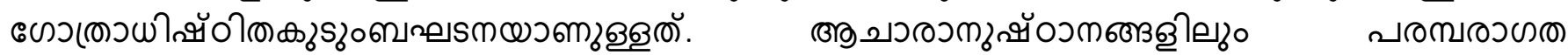

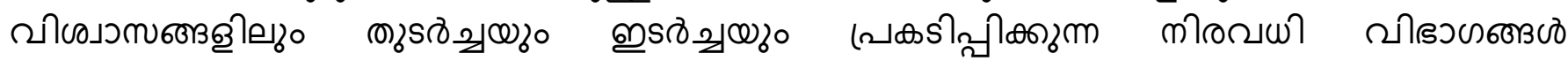

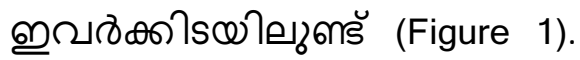

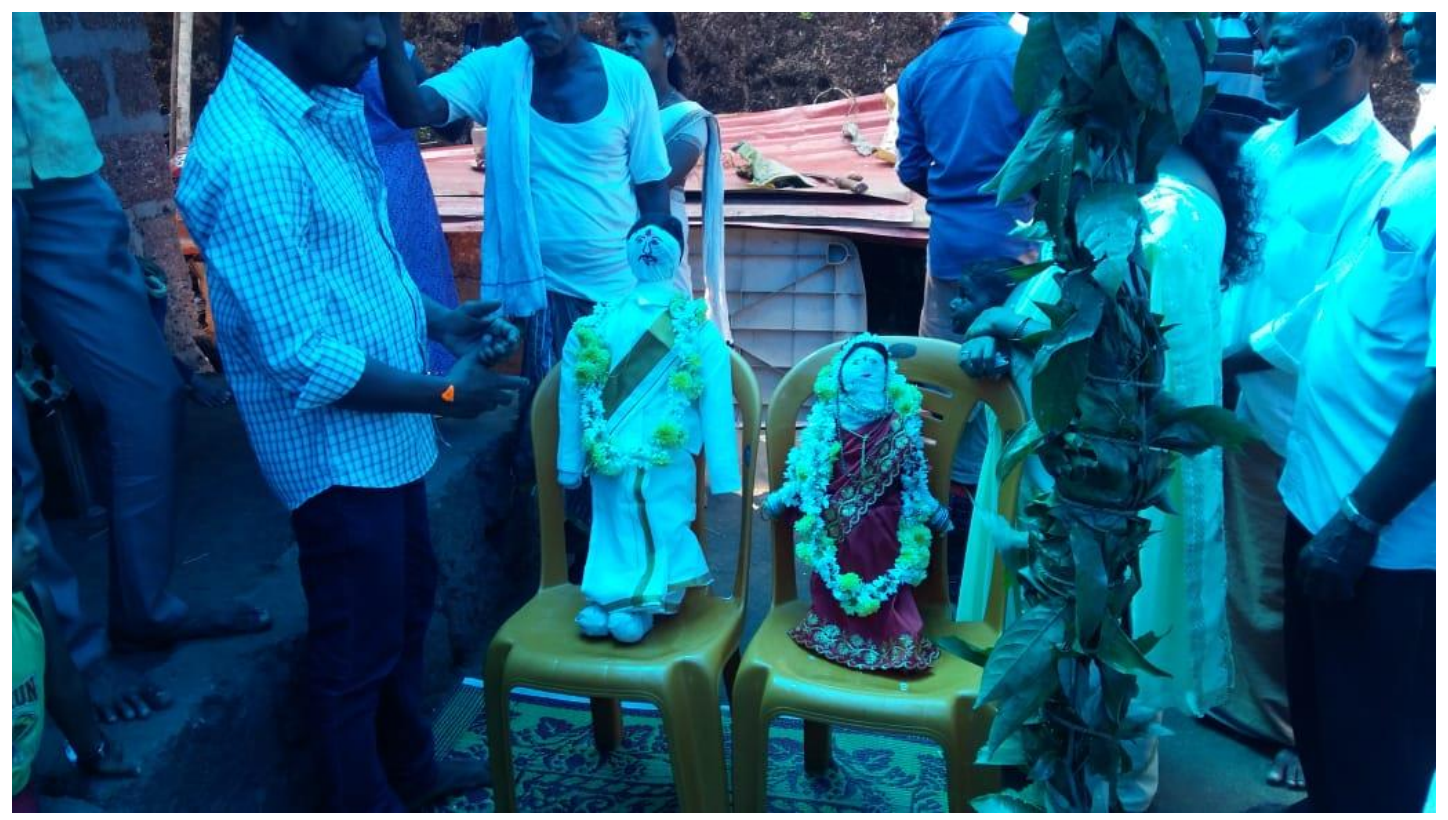

Figure 1 Photo of the Marriage of the dead

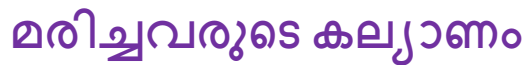

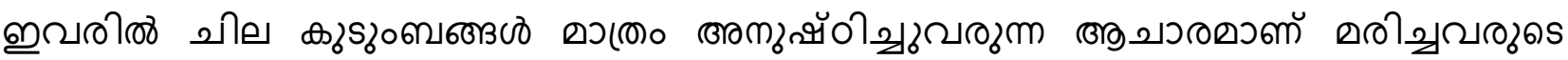

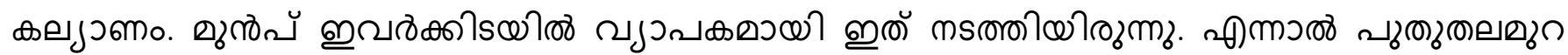

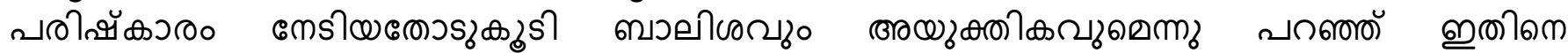

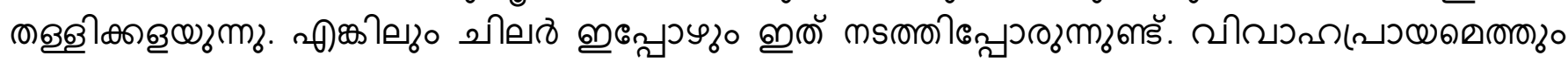

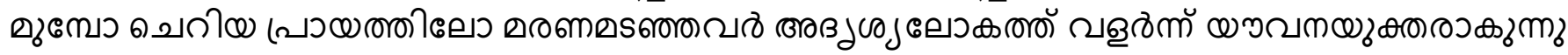

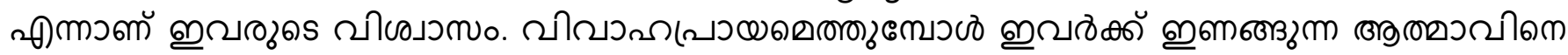

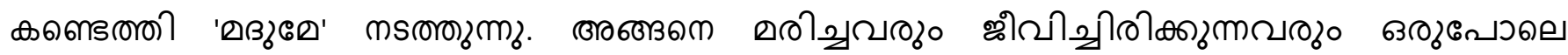

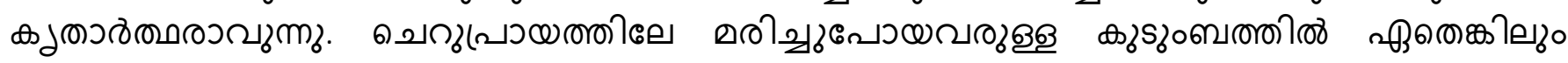




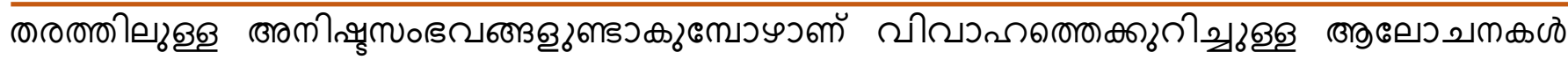

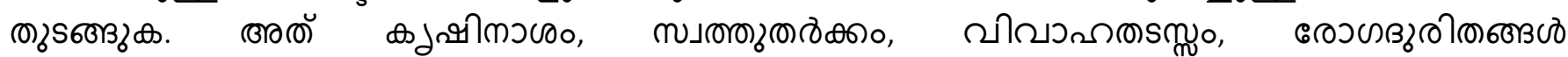

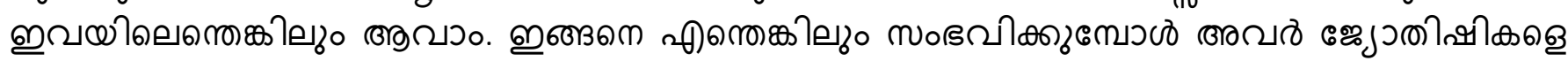

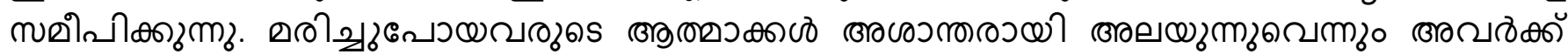

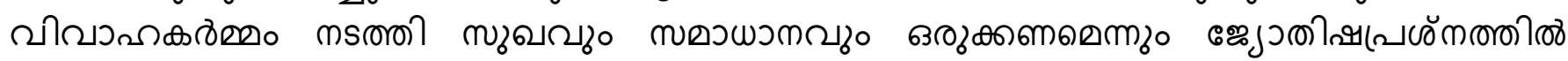

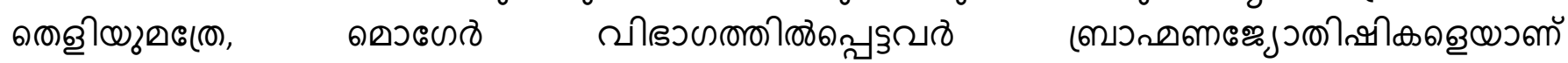

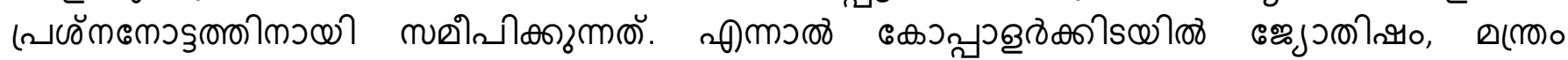

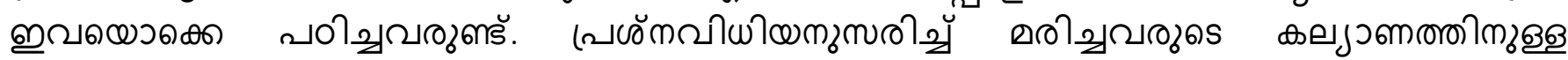

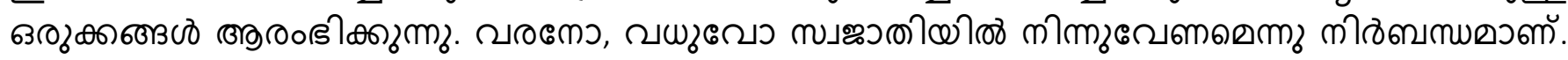

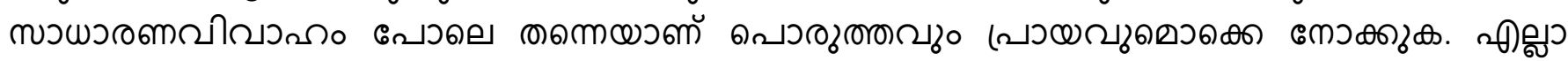

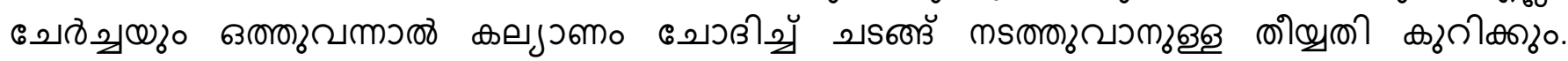

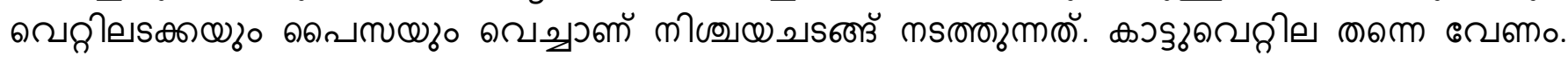

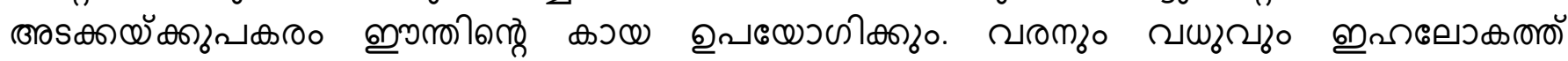

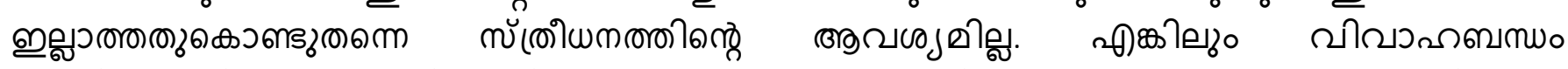

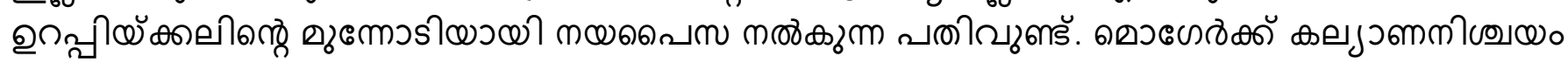

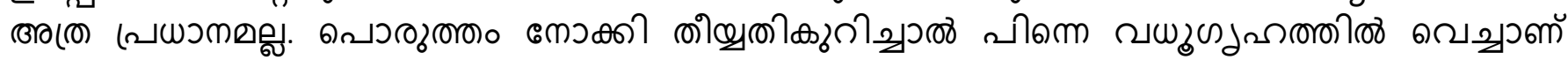

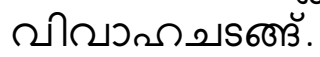

\section{SOBठक}

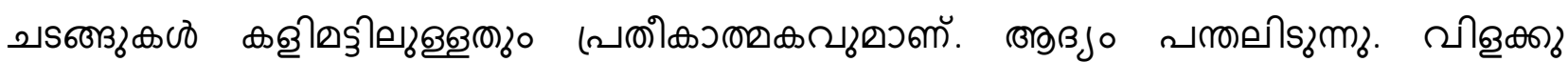

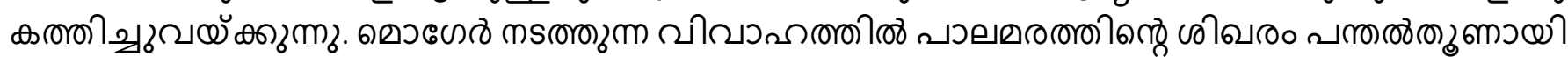

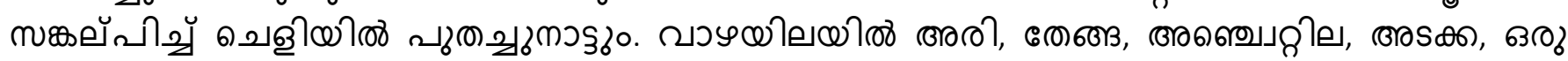

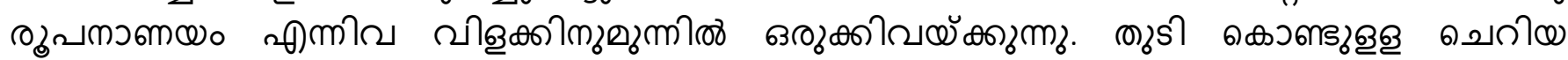

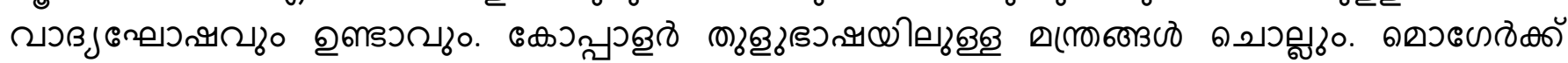

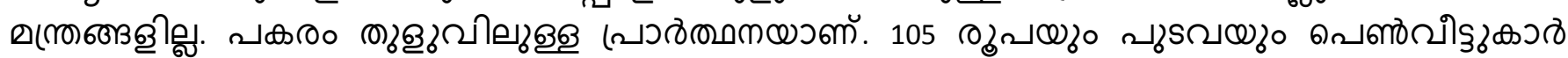

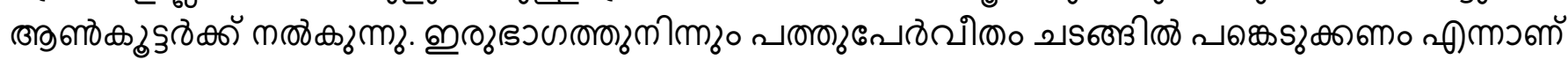

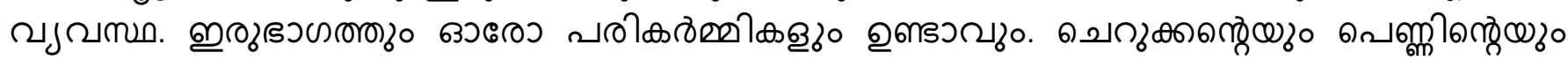

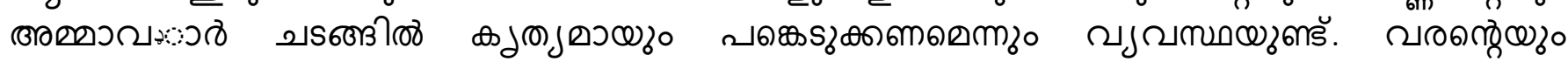

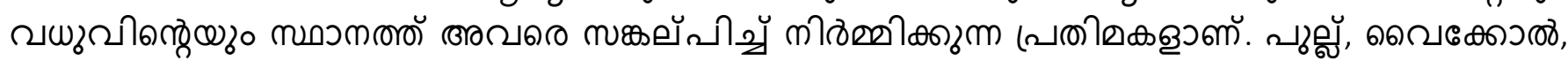

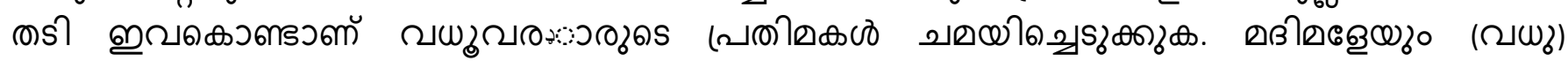

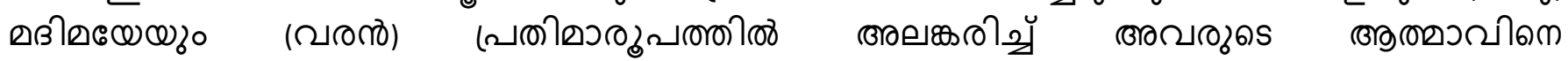

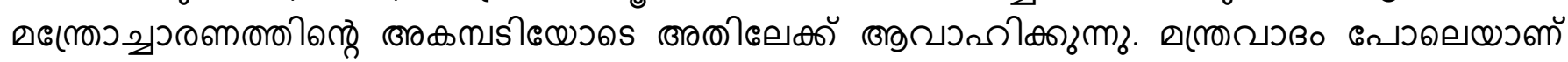

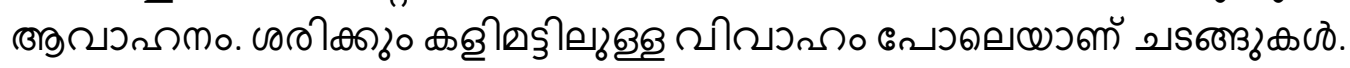

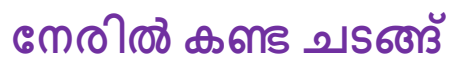

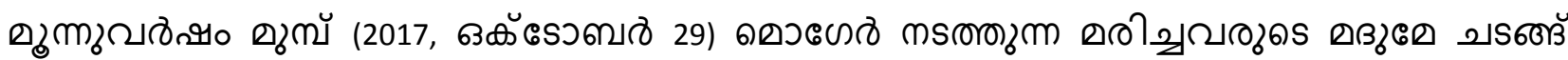

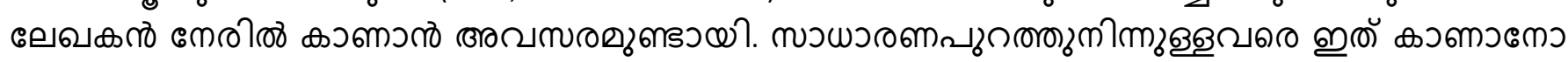

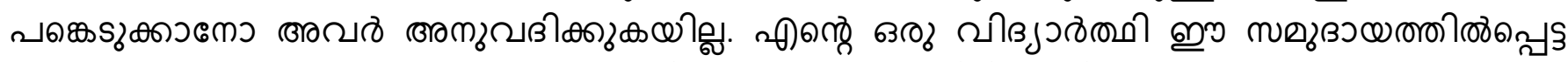

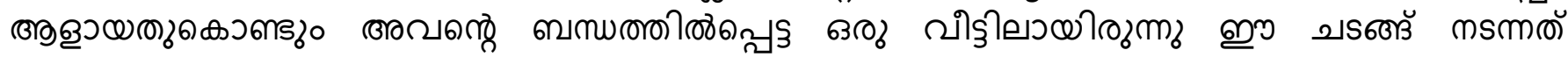

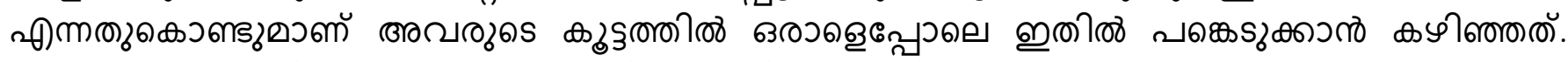

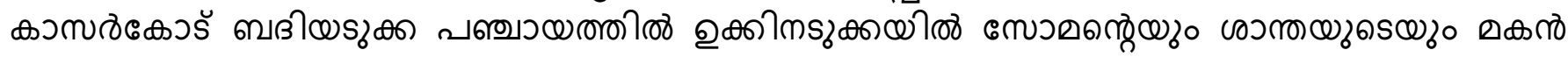

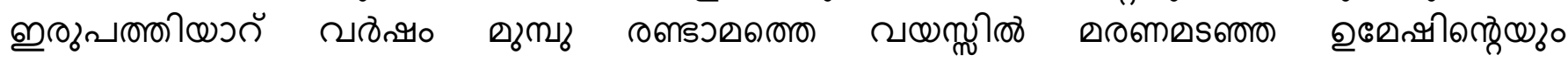




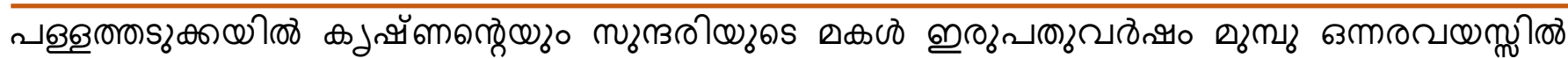

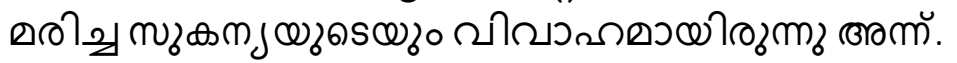

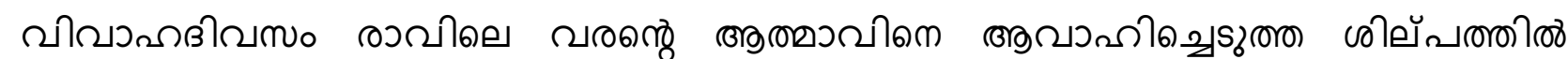

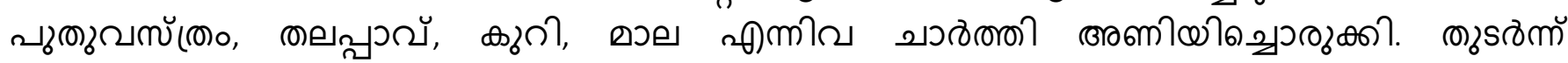

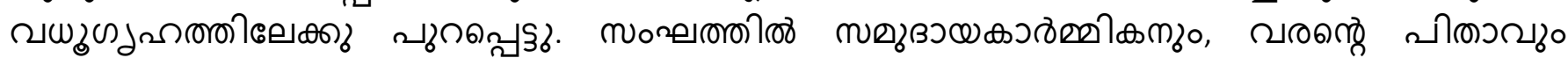

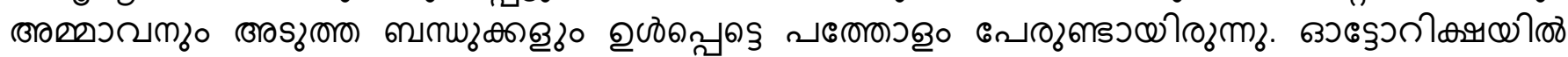

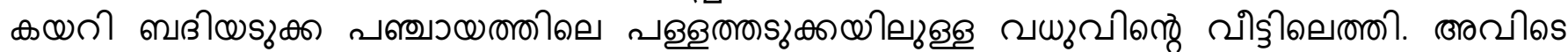

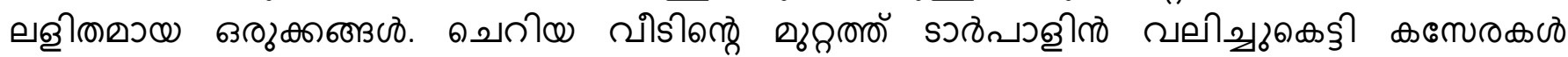

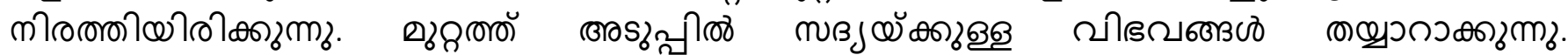

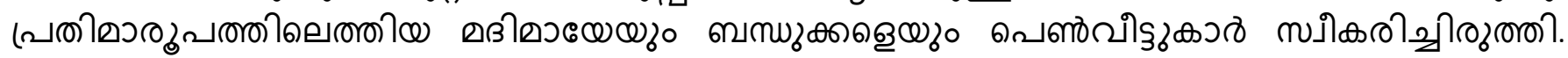

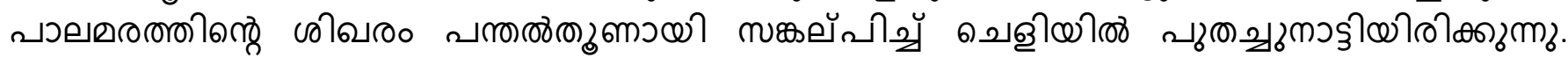

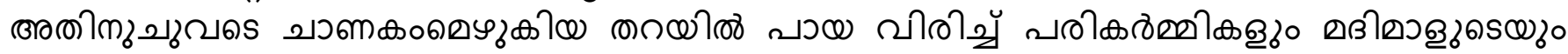

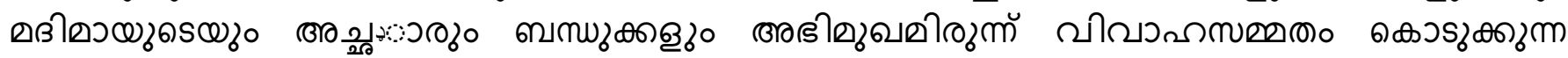

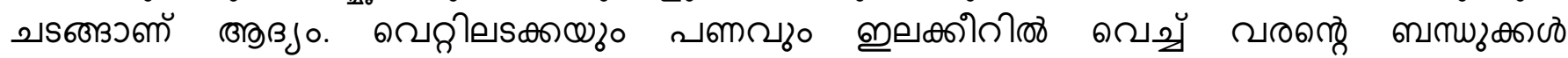

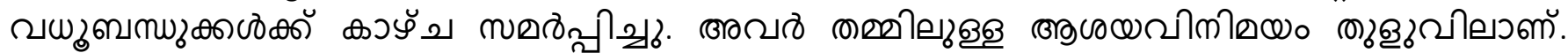

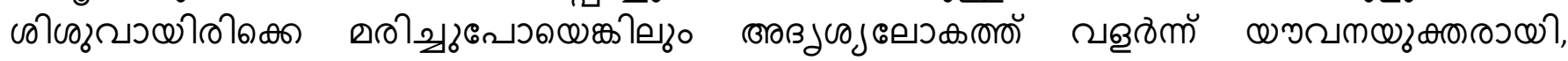

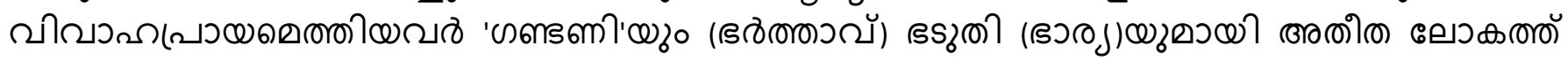

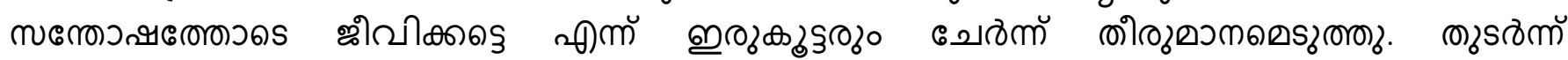

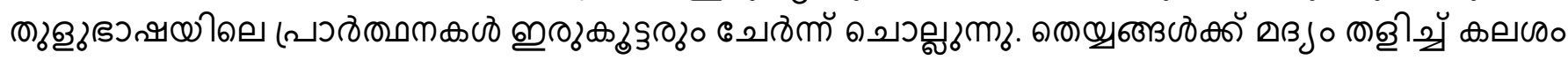

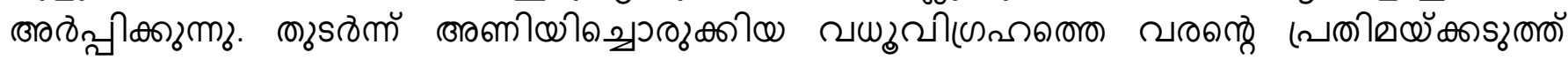

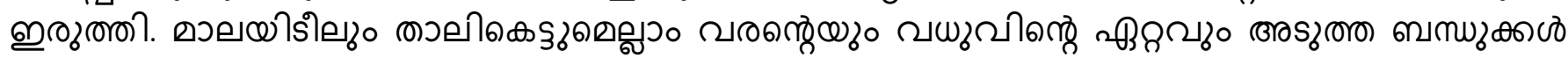

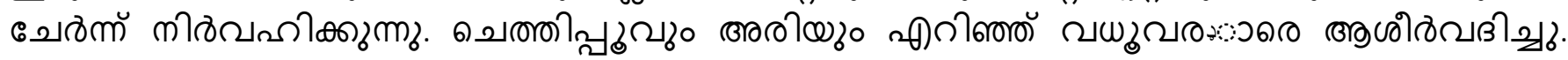

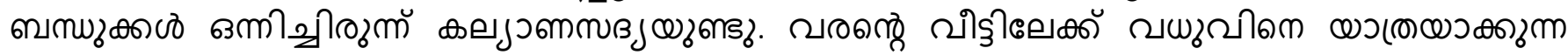

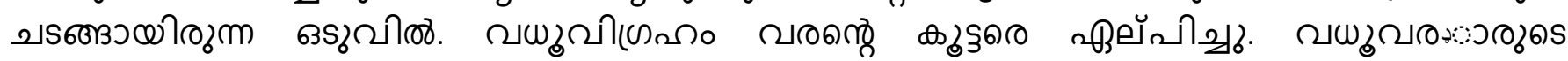

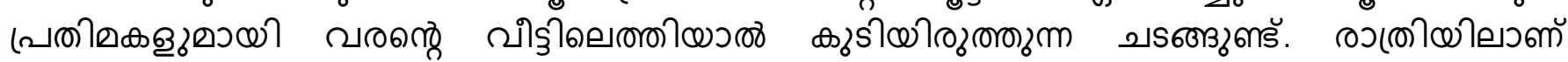

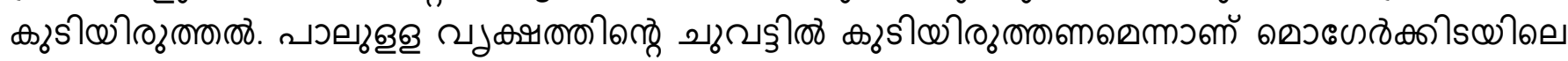

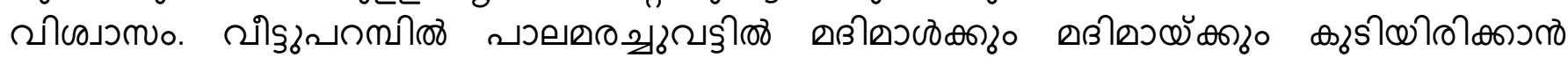

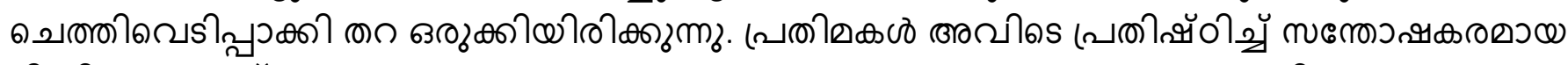

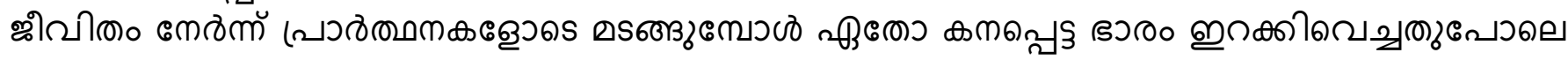

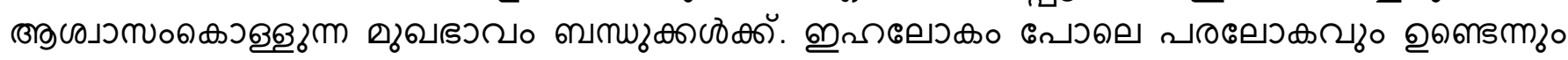

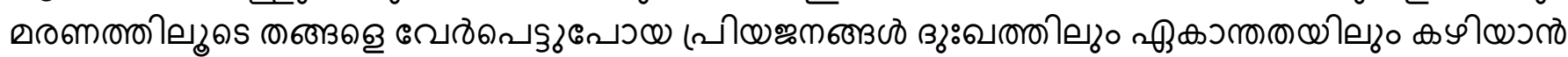

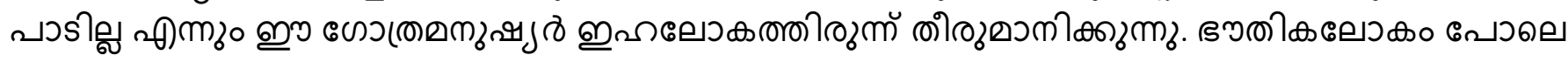

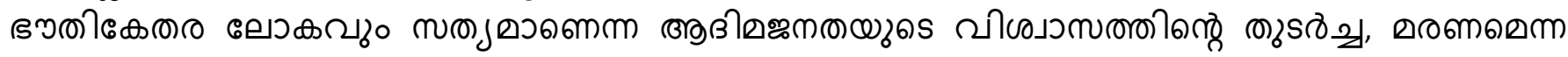

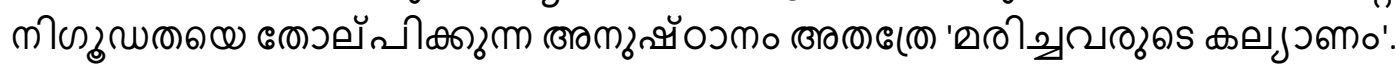

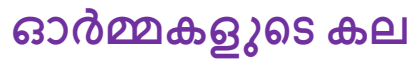

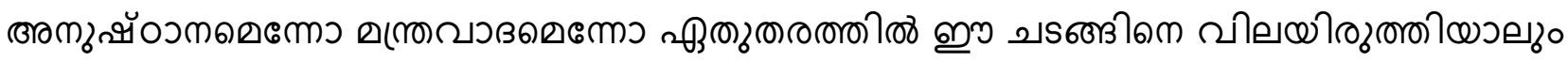

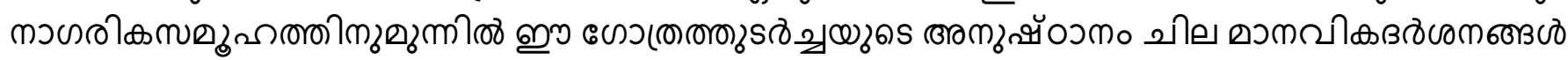

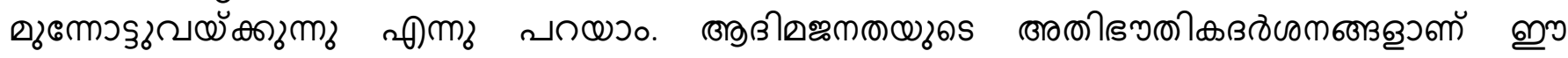

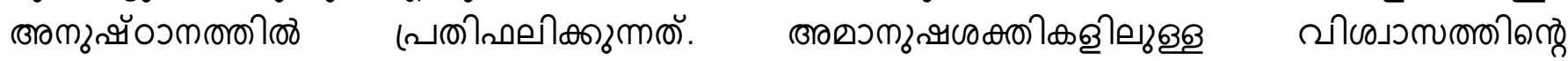

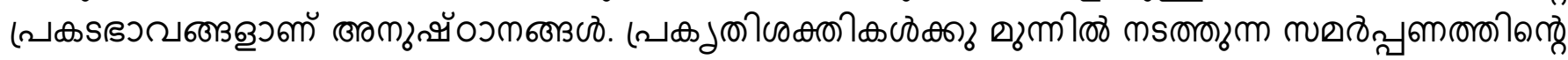

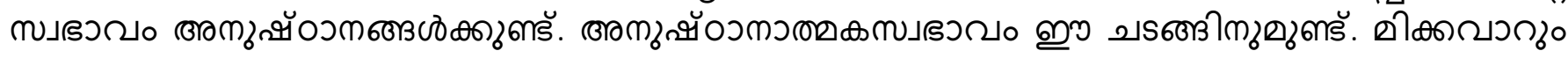

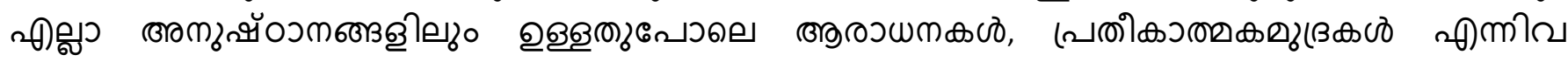




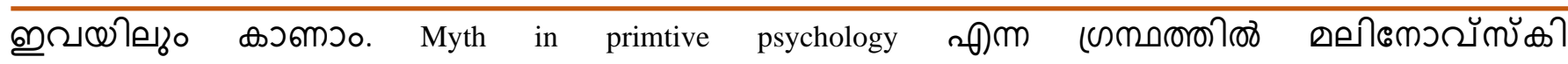
Ш ஈ

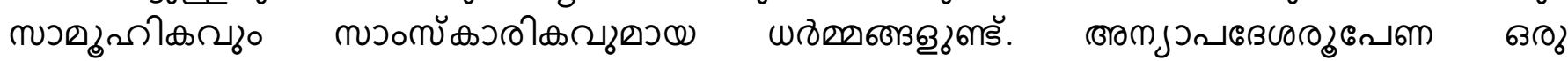

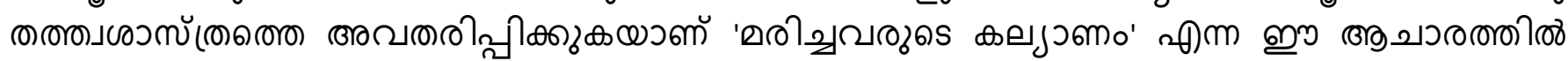

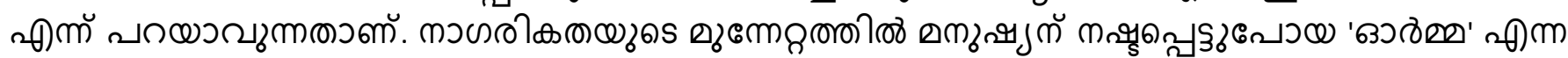

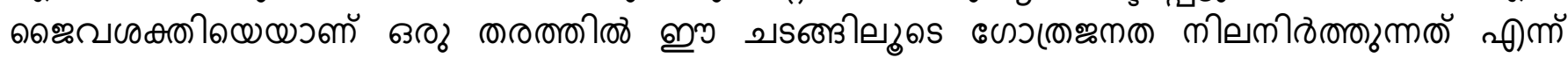

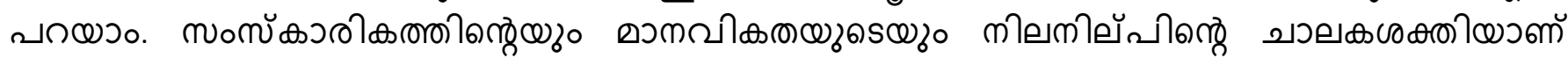

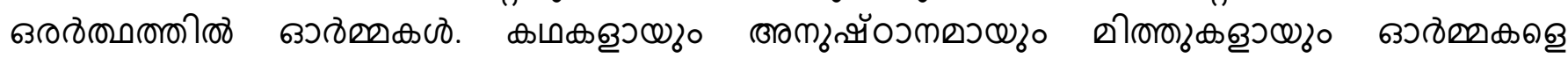

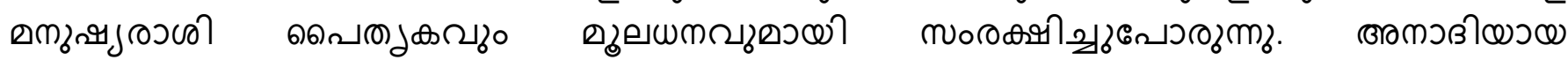

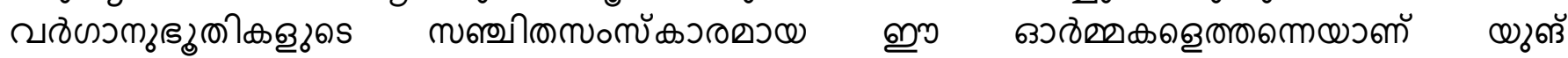

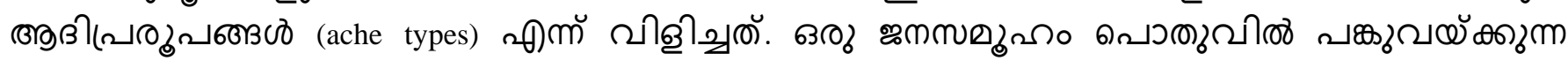

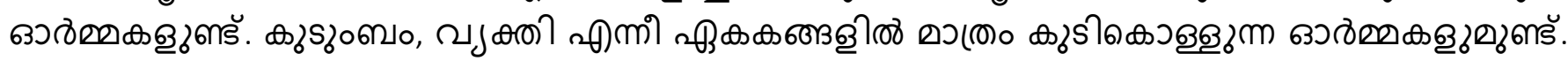

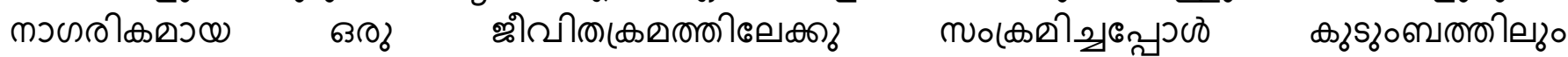

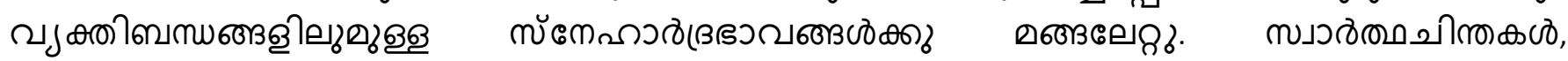

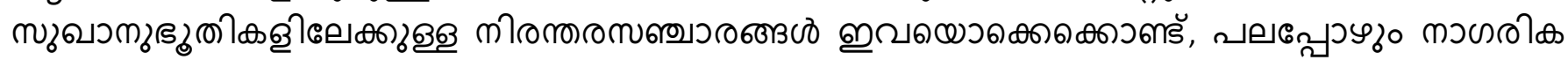

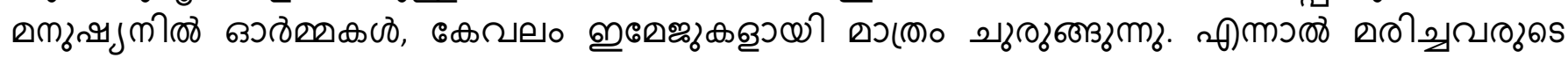

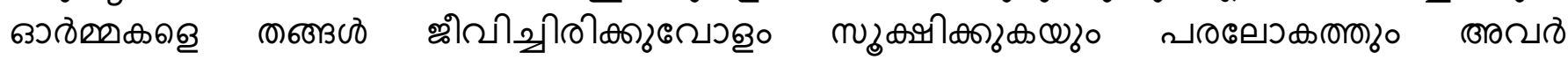

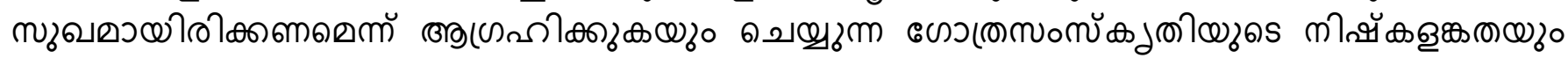

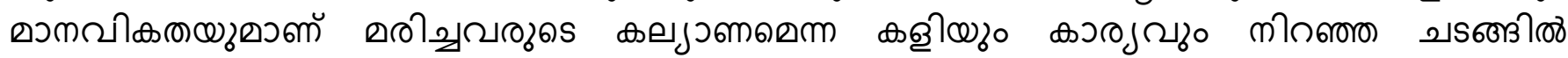

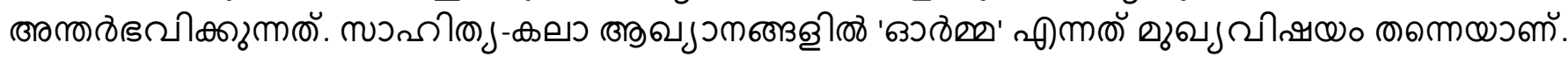

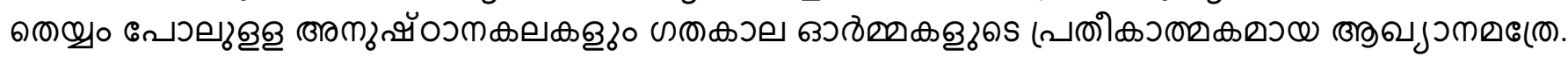

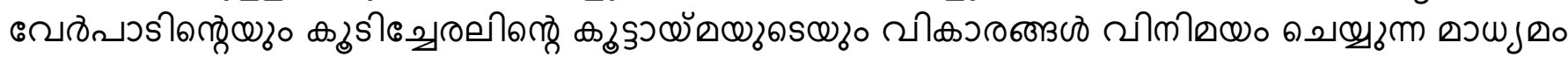

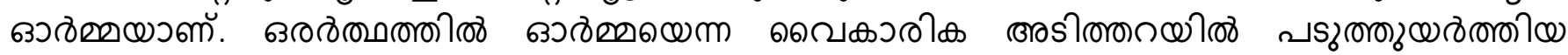

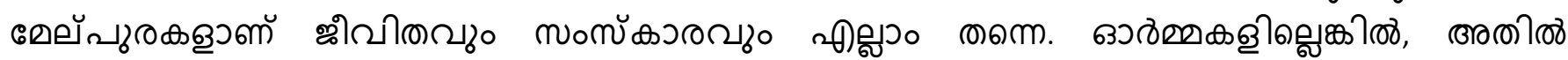

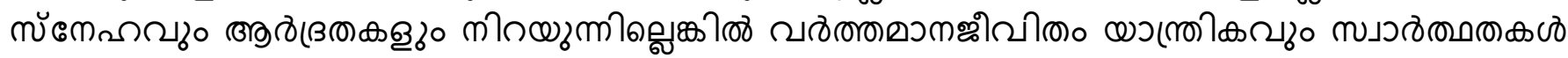

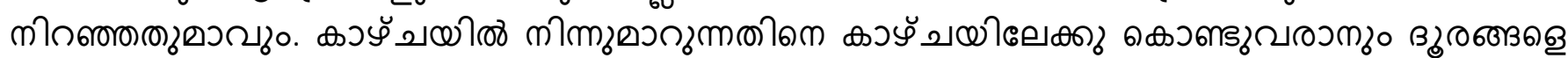

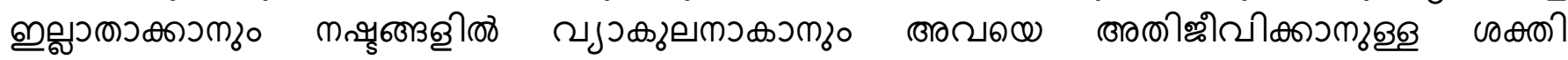

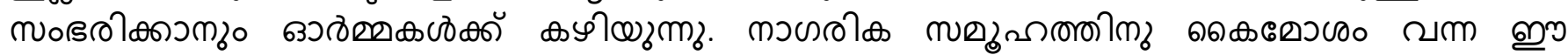

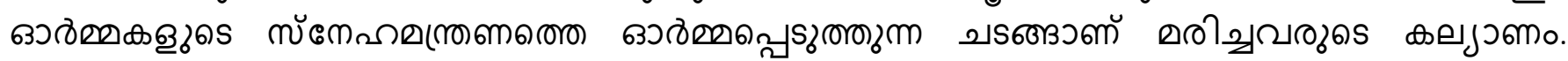

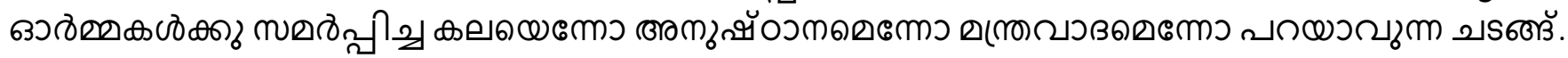

\section{Conclusion}

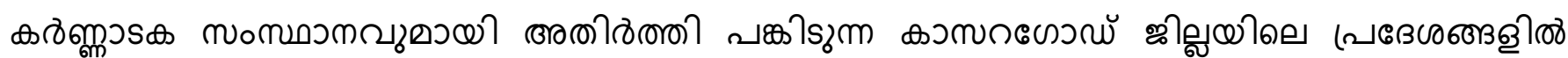

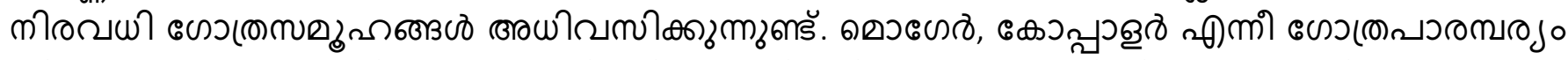

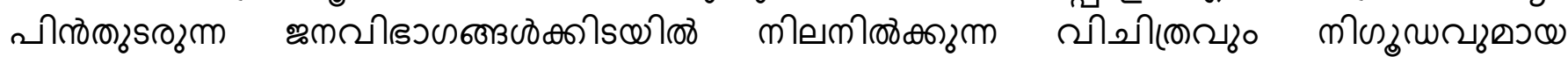

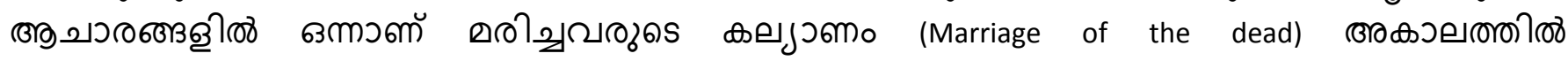

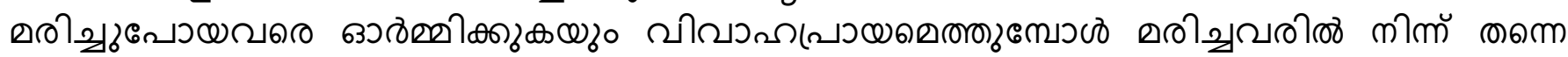

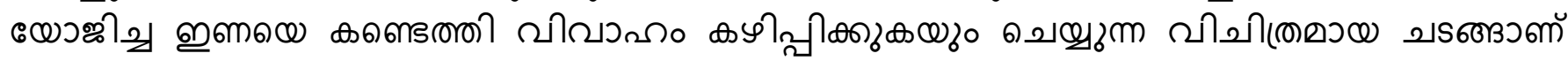

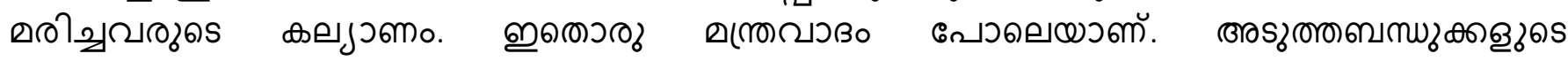

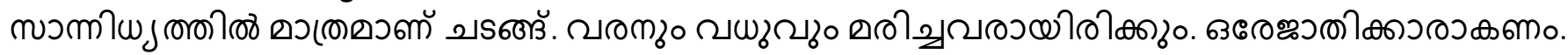

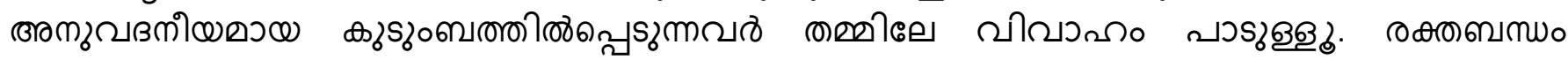

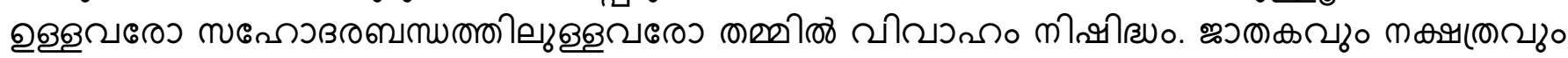

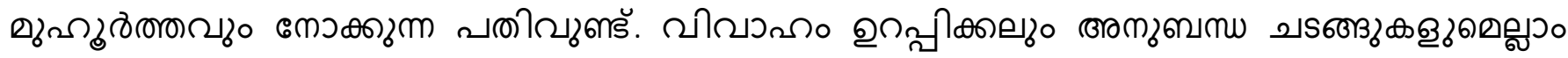




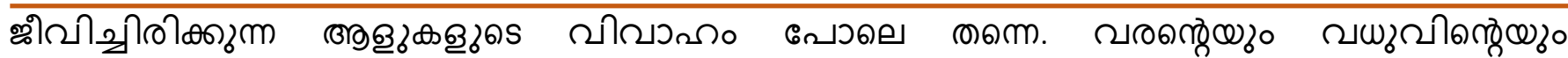

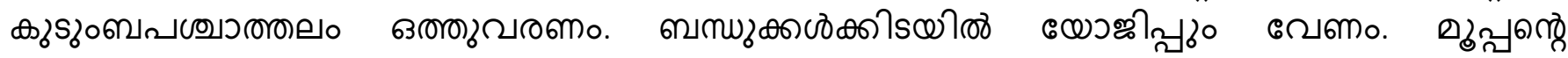

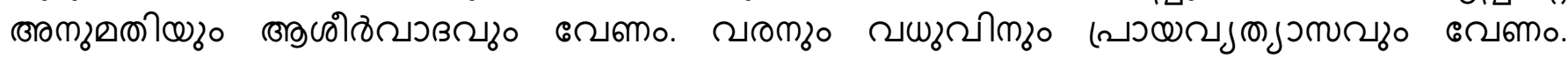

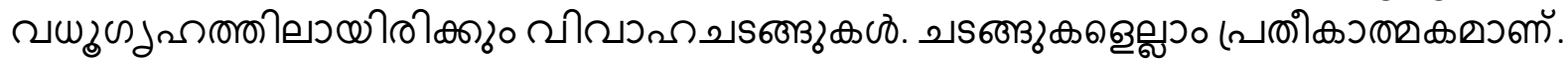

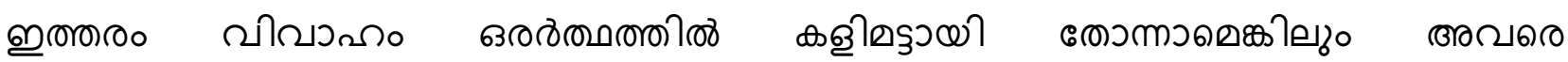

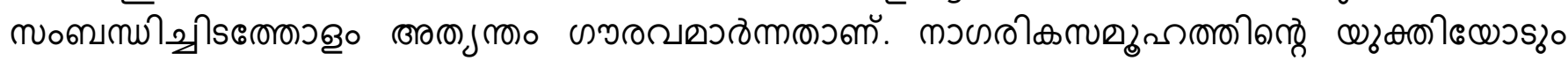

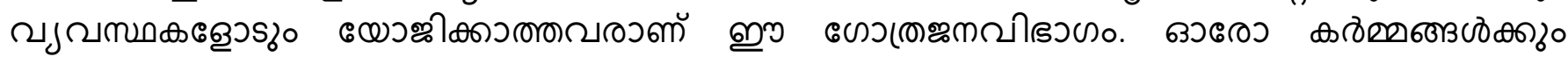

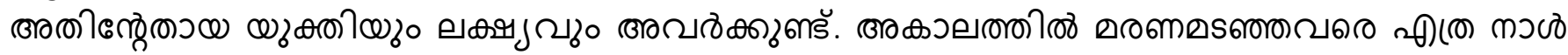

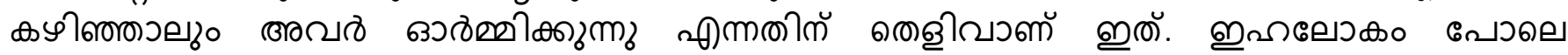

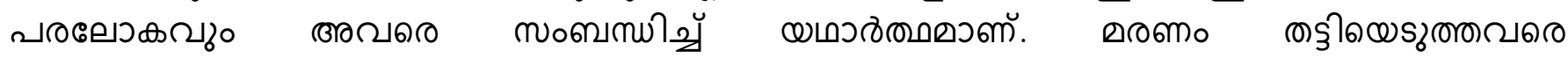

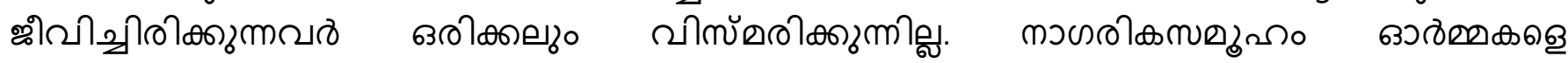

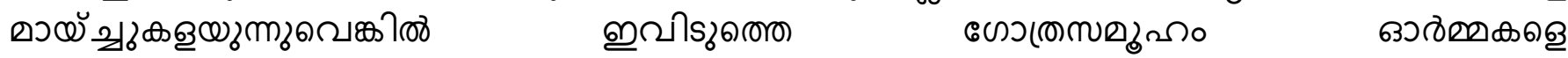

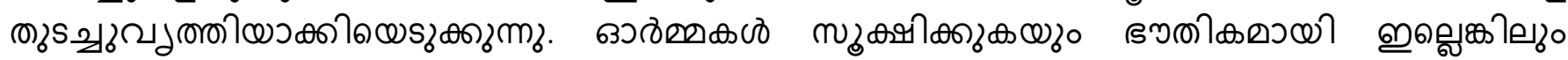

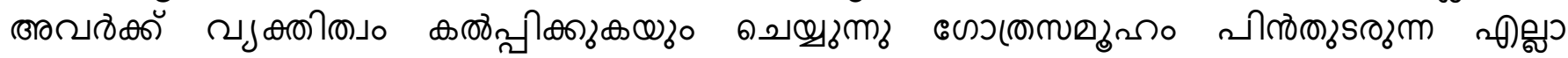

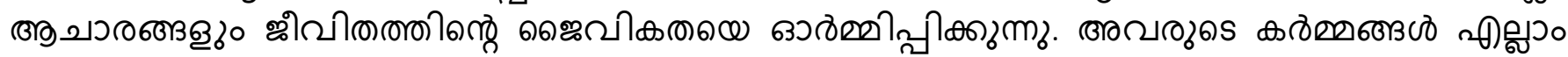

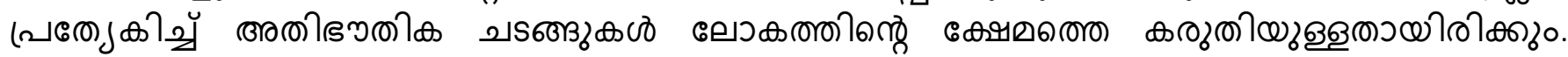

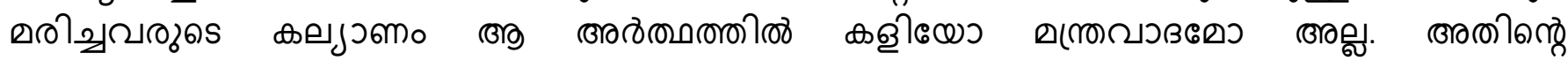

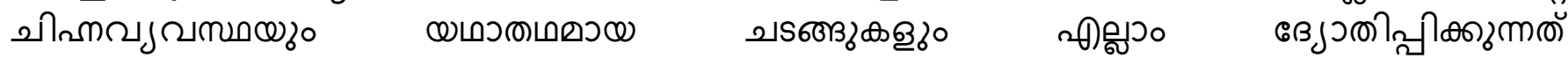

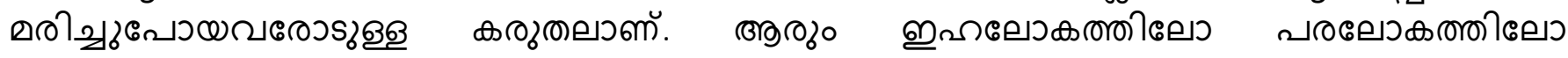

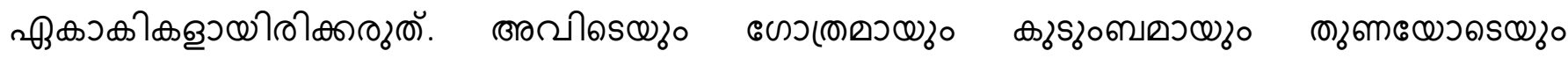

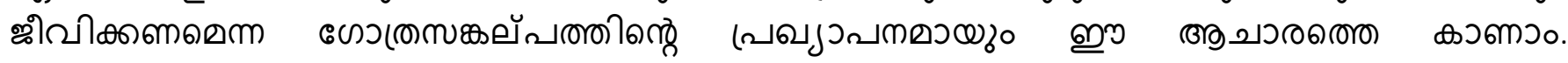

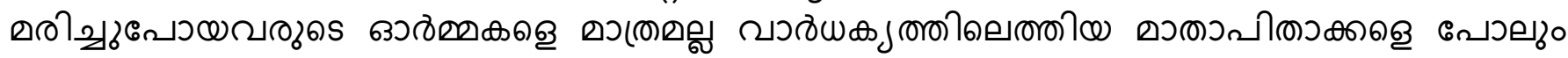

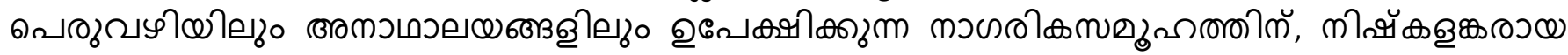

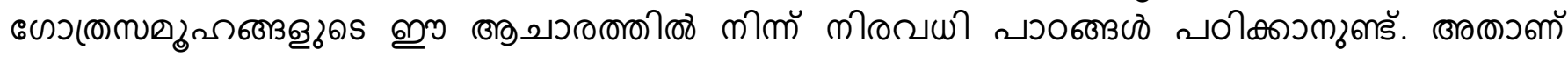
வலी श्र

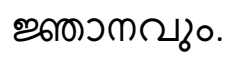

\section{References}

Malinowsky. B., (1974) Magic Science and Religion, New york, Double Day Anchor Books. Jung, C.G., (2001) Psychology and Religion, Routlegde and Kegan Paul, London.

Mathrubhoomi weekend magazine (2017) November 19.

Raveendran Padi, (2020) Thulunadu Mudrakal, Aa Books Kasargod, Kerala, India.

\section{Funding}

No funding was received for conducting this study.

\section{Conflict of interest}

The Author has no conflicts of interest to declare that they are relevant to the content of this article. 
About The License

(C) The author 2020. The text of this article is open access and licensed under a Creative Commons Attribution 4.0 International License

\section{Cite this Article}

R. Chandrabose, An exploration of the Logic and wisdom behind the Marriage of the Dead, Indian Journal of Multilingual Research and Development, Vol 1, Iss 1 (2020) 34-40. DOI: https://doi.org/10.34256/ijmrd2015 